\title{
i-Class: A knowledge sharing peer-education platform
}

\author{
Liqi Zhao ${ }^{1, a}$,Xuan $\mathrm{Li}^{2, \mathrm{~b}}$, Xiaoyu $\mathrm{Hu}^{2, \mathrm{c}}$, Yile $\mathrm{Liu}^{2, \mathrm{~d}}$, Jinghui $\mathrm{Xu}^{2, \mathrm{e}},{ }^{2}$ Chen Wang ${ }^{1, \mathrm{f}}$ \\ andHao $\mathrm{Xu}^{2, \mathrm{~g}^{*}}$, \\ ${ }^{1}$ College of Software, Jilin University, Changchun 130012, China; \\ ${ }^{2}$ College of Computer Science and Technology, Jilin University, Changchun 130012, China; \\ azhaolq5512@mails.jlu.edu.cn, ${ }^{\mathrm{b}}$ lixuan2112@mails.jlu.edu.cn

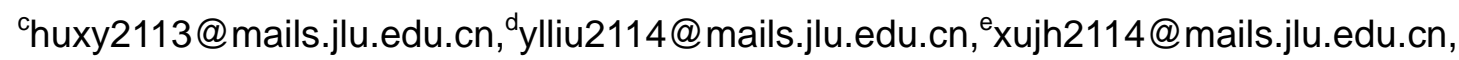 \\ fwangchen14@mails.jlu.edu.cn, ${ }^{9} x u h a o @ j l u . e d u . c n$, \\ ${ }^{*}$ Corresponding Author
}

Keywords: peer-education, university education, resource sharing, C2C, WeChat

\begin{abstract}
The traditional education lacks of individual education such as one's entrance exam for the postgraduate school, work interviews and practical aspects of entrepreneurship. Currently many popular internet education platforms whose connection is from person to the course use B2C operating mode, in which students have to choose existing courses while being ignored their requirements of the course. In the early market research, we find there are some study obstacles among students who prepare for the final exam and who prepare for the entrance exam of postgraduates. To solve the problem without using some high-paid organizations, we try to use students'idle teaching resource which matches the concept“everyone can be the teacher".In this paper we design and implement an innovative data-driven platform namedi-Class that assists students to connect with teachers who can solve their problems about studying.Particularly,these teachers actually come from the students without any limitation. Through the platform, students have access to the suitable teachers then realize resource sharing and peer-education.
\end{abstract}

\section{Introduction}

Nowadays, Uber and Airbnb have overturned the traditional transportation and lodging industry. Since social idle traffic and housing resources are integrated with network products to solve social problems, it's potential that the future of education could also be changed into a new mixed mode. Based on the B2C model,"Genshuixue" is an education website emphasizing on choosing a good teacher who is professional on one's field[1]. In universities,many students spend much on organizations to learn job skills, programming and etc, where they cannot learn from textbooks. Yet, many teachers are college students. Why not we just create an online platform which connects teachers and students as well as cutting the high cost organizations? In view of the needs,i-class is committed to creating a C2C(Customer to Customer) education platform, in which anyone basing on "will to learn"(usually college students)can play a role as a teacher or a student[2,3].No matter who can release the information online asking for someone to help or choose to teach others then meet offline .The platform can also be available for those who have difficulties in final exam reviews.

According to the former analysis on potential users, we find that many students are willing to teach peer. During these peer-education courses, there can also be a chance for both sides strengthening detailed learning and gain confidence[4]. Being in a quite active college students group, they would like to know more like-minded friends and are glad to share or accepting new things. The teachers and students of platform are mainly from college students, that's why substantial money will not be required firstly. But focusing on the cultivation of the user's habits and building trust mechanism according to the basic identity authentication in the platform are the first task.

i-class is trying to provide students with more targeted learning and provide a platform for same 
education background people sharing knowledge and building social networks.

\section{Platform Design}

In order to reach more users, we choose to build up a subscription account on WeChatinitially. WeChat is a mobile-born messaging servicewhich has already owned more than 500 million active users from previous market investigation. According to our product concept"everyone can be the teacher",the platform is divided into three elementary parts"participate an exist course, pursue a new course and join us". These three functions are well connected with each other to cover common needs(depicted in Fig.1).

\section{A. Participate an exist course}

Firstly, consisted of four auxiliary elements,this parthas the whole usage procedure for the user as a student. Being released openly including educational background, specialty,hobby,life attitude as well as former courses comments,teachers' information contributes to a more efficient teacher-student match pattern than the traditional one. After users sign up a course as students, the corresponding information will be sent to the teacher and also be recorded in data base. For the teacher who gets suggestions or requests noted by students,he/she could make a more detailed preparation which benefits both sides.If you are ready to share your knowledge,you can submit one information form to us and we also provide teachers information changing service later on.After the authentication executed sternly by our team,you could be a teacher here!"Recent courses" is the place where you can find the popular and afoot courses.

\section{B. Pursue a new course}

Secondly, this part is based on the former part.This function allows users to release the course information which they want and also browse other wanted courses which they could joinon the basis of individual's preference. For the users who have already been authenticated have the qualification to organize a new course on demand.

\section{Join us}

Finally,the left part will show hot recommendations sorted out by atmosphere in class,evaluation after class and the welcome extent of teachers.The courses comments also help to build a social education[4]. If you still cannot understand how this works,follow us. We will unfold i-class story on "About Us"regularly,maybe you would like to join us after you experience this novel social peer-education fashion.

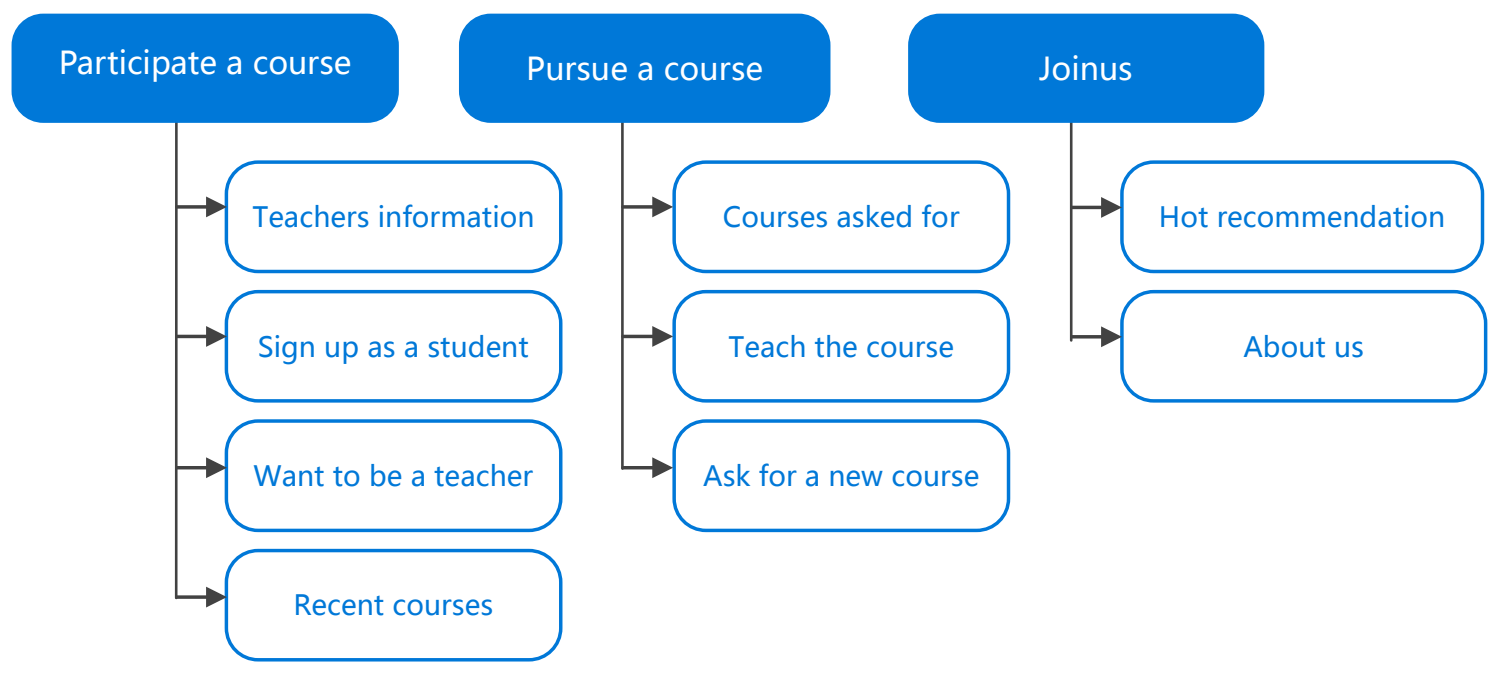

Figure 1. Model of Platform

\section{Implementation}

In early days,we sent out questionnaires through WeChat to investigate the most needed guidance courses at the end of the term among students majored in computer science and we got a 
top 5 list.Apart from pushing notification on our own account,we also got supported by one of the most popular official accounts 'jluhsy' in our university,which makes us get more than 3000page views in just one night. For the first round,we have authenticated 11teachers whose degrees cover from freshman to the second year of master.In the meantime,we held courses 7times in total.Other than advanced mathematics,physics and $\mathrm{C}++$ program,we also organized public class concerningthe experience studying abroad.There are more than one hundred students who provide us feedback and proposals attending the offline course.

\section{Data Analysis}

Prophase preparation is to look into the attitude of normal marks students towards to first-rate students --a group of students who always get good marks in exams.Over 70 percent of informants indicate that they would like to consult with first-rate students while actually they cannot.Based on the issue, we continued digging out one deep reason.

70.4 percentages of informants feel sorry about questioning too much leading to hold up much time of first-rate students especially during the tense terminal review time.And other $24.7 \%$ informants consider that they have no acquaintance with first-rate students which becomes one of the main study hinders before exams. The others who have multiple reasons such as too lazy to ask for questions or prefer study by oneself and so on just occupy a light part(Fig.2).

From the data statistics,it's not hard to tell that there is a potential and strong market in peer-education before thefinal examination.In the meantime,there are also 30\%first-rate students agreeing with the idea that sharing their acknowledge in return to get paid,teaching experience or well-connected relationship with others is worth.Along with the promotion of i-class's publicity during the commissioning,the attendance of students is on the increase despite the remain hesitant parts.(Fig.3 shows the tendency.)Yet,there are a certain part of students who are not engaged well,which needs peer-instruction we believe after the courses[4].
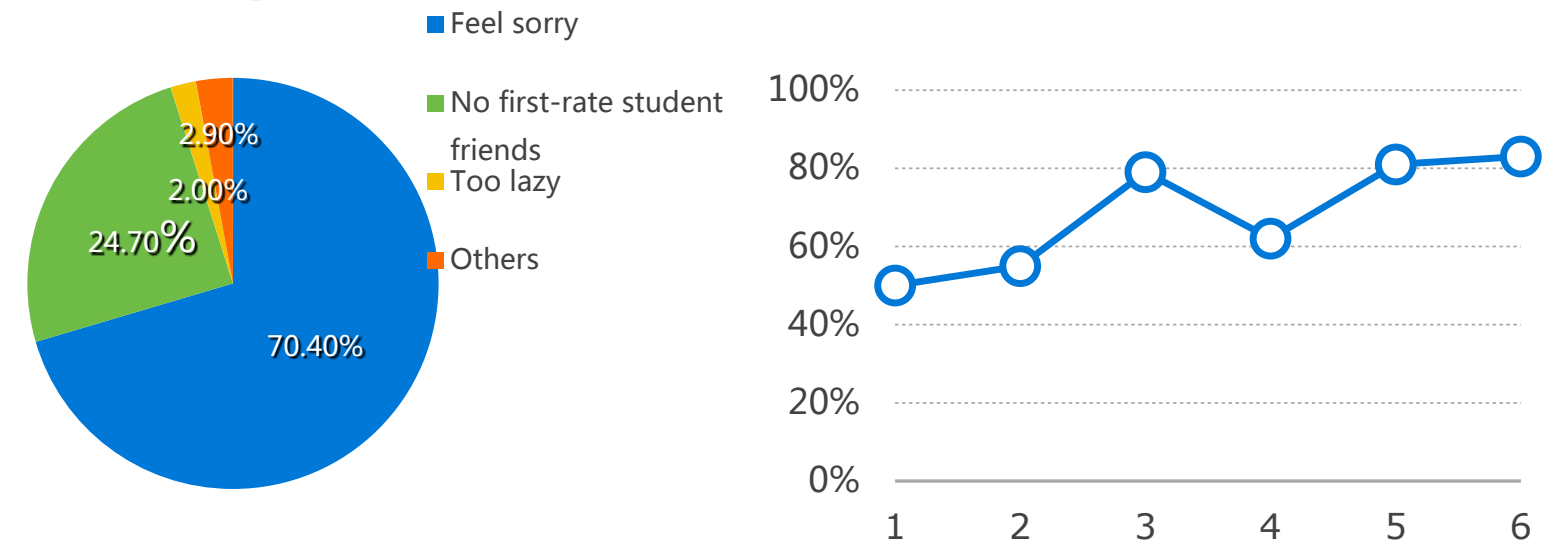

Figure 2.Reasons analysis Figure 3. Increasing tendency

\section{Conclusion}

Unlike Skillshare,which is a skill sharing P2P website based on cities,i-class is targeting atcollege students as main users[7]. We combine online demand with offline service taking advantage of unexploited education resource. After the public courses,more and more students are following our official account,willing to join the courses and applying to sign up as a teacher.All of the progress we have achieved cheer the whole team up and impel us to improve and perfect the platform more handily and humanly.

In the near future,i-class will keep propagating the idea,broadening the scope of the course and perfect the procedure of authenticating a teacher.APP client and the website will also be launched if necessary.With the accumulation of user quantity,we will charge properly and expand the service to the society,though it's a long way to go.One thing we can be sure of is the concept--everyone can be 
the teacher--will finally benefits universities even the whole society as long as being taken seriously.

\section{Acknowledgement}

This work is supported by the National Natural Science Foundation of China (No. 61300147), China Postdoctoral Science Foundation (No. 2014M551185), the Science and Technology Program of Changchun (No. 14GH014) and the Erasmus Mundus Swap and Transfer Project of the EU Commission.

\section{References}

[1].the website of "gensheixue”, http://cc.genshuixue.com/

[2].Dong Hong Zhu,Ya Ping Chang,Jian Jun Luo,Understanding the Influence of C2C communication on purchase decision in online communities from a perspective of information adoption model ,Telematics and Informatics 33(2016)8-16

[3].ValdaMcCune,NoelEntwistle,Cultivating the disposition to understand in 21st century university education,Learning and Individual Differences, 2010, Vol.21 (3), pp.303-310

[4].Cortright Ronald N,Collins Heidi L,DiCarlo Stephen E,Peer instruction enhanced meaningful learning: ability to solve novel problems, Advances in Physiology Education, 2005, Vol.29 (2), pp.107-11

[5].Hao Xu,YutaoBie,Social JLU:Towards Building Social Learning Networks,International Conference on Education Technology and Information System(ICETIS 2013)

[6].Nicolas Michinov,JulienMorice,VincentFerrieres,A step further in Peer Instruction:Using the Stepladder technique to improve learning,Computers\&Education91(2015)1-13

[7].Skillshare, online classes website, https://www.skillshare.com/ 